\title{
Pulmonary embolism in patients with coronavirus disease-2019 (COVID-19) pneumonia: a narrative review
}

\author{
Yasser Sakr ${ }^{*}$, Manuela Giovini ${ }^{2}$, Marc Leone ${ }^{3}$, Giacinto Pizzilli' ${ }^{4}$ Andreas Kortgen ${ }^{1}$, Michael Bauer ${ }^{1}$, \\ Tommaso Tonetti ${ }^{4}$, Gary Duclos ${ }^{3}$, Laurent Zieleskiewicz ${ }^{3}$, Samuel Buschbeck', V. Marco Ranieri ${ }^{4}$ \\ and Elio Antonucci ${ }^{2}$
}

\begin{abstract}
Background: Preliminary reports have described significant procoagulant events in patients with coronavirus disease-2019 (COVID-19), including life-threatening pulmonary embolism (PE).

Main text: We review the current data on the epidemiology, the possible underlying pathophysiologic mechanisms, and the therapeutic implications of PE in relation to COVID-19. The incidence of PE is reported to be around 2.6-8.9\% of COVID-19 in hospitalized patients and up to one-third of those requiring intensive care unit (ICU) admission, despite standard prophylactic anticoagulation. This may be explained by direct and indirect pathologic consequences of COVID-19, complement activation, cytokine release, endothelial dysfunction, and interactions between different types of blood cells.

Conclusion: Thromboprophylaxis should be started in all patients with suspected or confirmed COVID-19 admitted to the hospital. The use of an intermediate therapeutic dose of low molecular weight (LMWH) or unfractionated heparin can be considered on an individual basis in patients with multiple risk factors for venous thromboembolism, including critically ill patients admitted to the ICU. Decisions about extending prophylaxis with LMWH after hospital discharge should be made after balancing the reduced risk of venous thromboembolism (VTE) with the risk of increased bleeding events and should be continued for 7-14 days after hospital discharge or in the pre-hospital phase in case of pre-existing or persisting VTE risk factors. Therapeutic anticoagulation is the cornerstone in the management of patients with PE. Selection of an appropriate agent and correct dosing requires consideration of underlying comorbidities.
\end{abstract}

Keywords: SARS-CoV-2, COVID-19, Pulmonary embolism, Thromboprophylaxis, Venous thromboembolism

\section{Introduction}

Since the emergence of coronavirus disease-2019 (COVID-19) as a result of infection with Severe Acute Respiratory Syndrome Coronavirus 2 (SARS-CoV-2) [1], several reports have described significant procoagulant events, including life-threatening pulmonary embolism

\footnotetext{
*Correspondence: yasser.sakr@med.uni-jena.de

${ }^{1}$ Dept. of Anesthesiology and Intensive Care Medicine, Jena University Hospital, Am Klinikum 1, 07743 Jena, Germany

Full list of author information is available at the end of the article
}

(PE), in these patients [2-45]. Abnormalities of various coagulation parameters were frequently reported [46, 47] and have been linked to poor prognosis [48]. Unfortunately, little is known about the epidemiology and the pathophysiologic mechanisms underlying COVID-19-associated PE because of the lack of large prospective studies in this context. Understanding these aspects is crucial for the early diagnosis and appropriate management of this potentially fatal complication. In particular, the optimal dosage and duration of prophylactic anticoagulation
Springer Open

(c) The Author(s) 2020. This article is licensed under a Creative Commons Attribution 4.0 International License, which permits use, sharing, adaptation, distribution and reproduction in any medium or format, as long as you give appropriate credit to the original author(s) and the source, provide a link to the Creative Commons licence, and indicate if changes were made. The images or other third party material in this article are included in the article's Creative Commons licence, unless indicated otherwise in a credit line to the material. If material is not included in the article's Creative Commons licence and your intended use is not permitted by statutory regulation or exceeds the permitted use, you will need to obtain permission directly from the copyright holder. To view a copy of this licence, visit http://creativeco mmons.org/licenses/by/4.0/. 
are major concerns. Indeed, PE was reported to occur in critically ill COVID-19 patients despite thromboprophylaxis [31], questioning the possible role of the implementation of higher dosage of thromboprophylaxis than those used in the standard practice. In this report, we review the current literature on the subject to define the epidemiology, possible underlying pathophysiologic mechanisms, and therapeutic implications of PE in relation to COVID-19.

\section{Epidemiology and outcome of PE in COVID-19}

As of May 24, 2020, 27 case reports describing the clinical characteristics of 30 patients with COVID-19-associated PE have been published (Table 1) [2-28]. The median age of these patients was 59 years (interquartile range (IQ) 44-68 years, range $17-84$ years) and $18 / 30$ patients were male. One-third of the cases had no comorbid conditions prior to ICU admission. There was no detectable source of PE in most of the cases (24 patients, 80\%). Diagnosis of $\mathrm{PE}$ was made at a median of 11 days (IQ: 7-17, range: 4-22 days) from the onset of SARS-CoV-2 symptoms. In 20 patients (66.7\%), PE was bilateral; the majority of cases were treated with LMWH. Only 8 patients $(26.7 \%)$ had central PE, of which 2 patients died.

Few cohort studies have reported the epidemiology of PE in COVID-19 patients, irrespective of the severity of illness and need for hospital admission (Table 2). Most of these were retrospective cohorts [29, 30, 32-37, 39-42, 44] and probably underestimated the incidence of PE because of the lack of a systematic approach to screening for this complication. The epidemiologic estimates were also likely influenced by the relatively short follow-up periods and different severities of infection. In two large retrospective French cohorts, the incidence of $\mathrm{PE}$ among patients positive for SARS-CoV-2, regardless of whether they were or were not admitted to hospital, was 1.1 and $3.4 \%$, respectively $[29,30]$. Evidence of PE was found in $23-30 \%$ of patients who underwent CTA imaging. Interestingly, comorbid conditions were similar in patients with PE and those without $[29,30]$. We may speculate, therefore, that the occurrence of $\mathrm{PE}$ maybe related, at least in part, to the progression and severity of COVID19 illness and not only to the physiologic status prior to infection. Indeed, patients with COVID-19 infection and PE had higher D-dimer levels, indicating higher severity of illness and more pronounced inflammatory response, than those without PE [30].

The incidence of PE in hospitalized patients with COVID-19 has been reported to be around 1.9-8.9\% $[29,33,43,44]$. Again, the retrospective nature of the reported cohorts and the relatively short periods of follow-up may have underestimated the real incidence of PE. Critically ill COVID-19 patients requiring ICU admission seem to be at a higher risk of thromboembolic complications, especially $\mathrm{PE}$, which may occur in up to $26.6 \%$ of these patients [36]. In a prospective observational study of 150 patients admitted to four ICUs in two French hospitals, PE occurred in $16.7 \%$ of patients despite thromboprophylaxis [31]. The authors also reported that thromboembolic events were more common in COVID-19 patients with acute respiratory distress syndrome (ARDS) compared to a propensity score-matched historic ARDS cohort, underscoring the unique procoagulant effect of COVID-19 compared to other ARDS etiologies. A retrospective cohort of 184 patients with COVID-19 admitted to ICUs in three hospitals in the Netherlands reported that PE occurred in $13.6 \%$ of the patients despite anticoagulant therapy [32]. Interestingly, the incidence of PE increased to $33.3 \%$ when the follow-up was increased from 1 to 2 weeks [39], at a time when heightened awareness of the common occurrence of PE may have led to a higher index of suspicion and more diagnostic procedures to detect this complication. Likewise, Poissy et al. showed that $20.6 \%$ of patients admitted to a French ICU had PE within a median of 6 days following ICU admission despite anticoagulation [35]. These authors also found that the frequency of PE in COVID-19 patients was twice as high as the frequency in patients admitted to the ICU in a control period as well as in $40 \mathrm{ICU}$ patients with influenza.

The paucity of deep venous thrombosis (DVT) or other sources of VTE in COVID-19 patients with PE [31] may suggest that, at least in some cases, pulmonary thrombosis rather than embolism is the underlying lesion in these patients. Nonetheless, autopsy of 12 consecutive patients admitted to an academic medical center in Germany revealed DVT in 7 of 12 patients (58\%) in whom VTE was not suspected before death [38]. The prevalence of DVT in COVID-19 patients may, therefore, have been underestimated because of the lack of repeated screening in these patients. The authors also reported that PE was the direct cause of death in one-third of patients, confirming the clinical relevance of this complication [38]. Another autopsy study in 11 COVID-19 patients found that death may be caused by the thrombosis observed in segmental and subsegmental pulmonary arterial vessels in all patients, despite the use of prophylactic anticoagulation [45]. Taken together, whereas the current evidence may not support the routine screening for DVT in COVID-19 patients as recommended by the International Society of Thrombosis and Haemostasis (ISTH) [49], high degree of clinical suspicion in diagnosing DVT should be adopted in these patients based on both clinical manifestations and laboratory data. Patients with otherwise unexplained deterioration in the clinical picture, those with local signs 


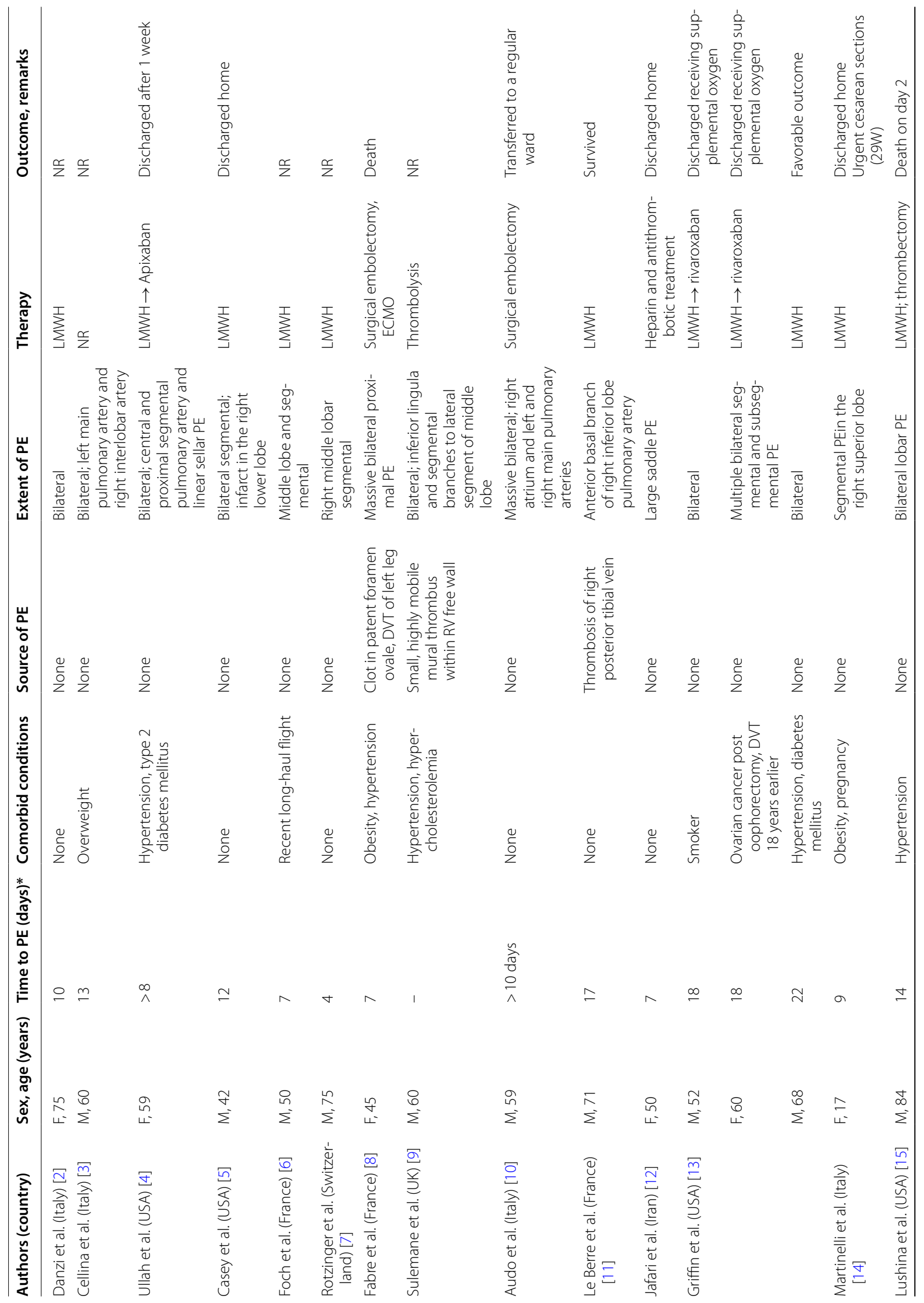




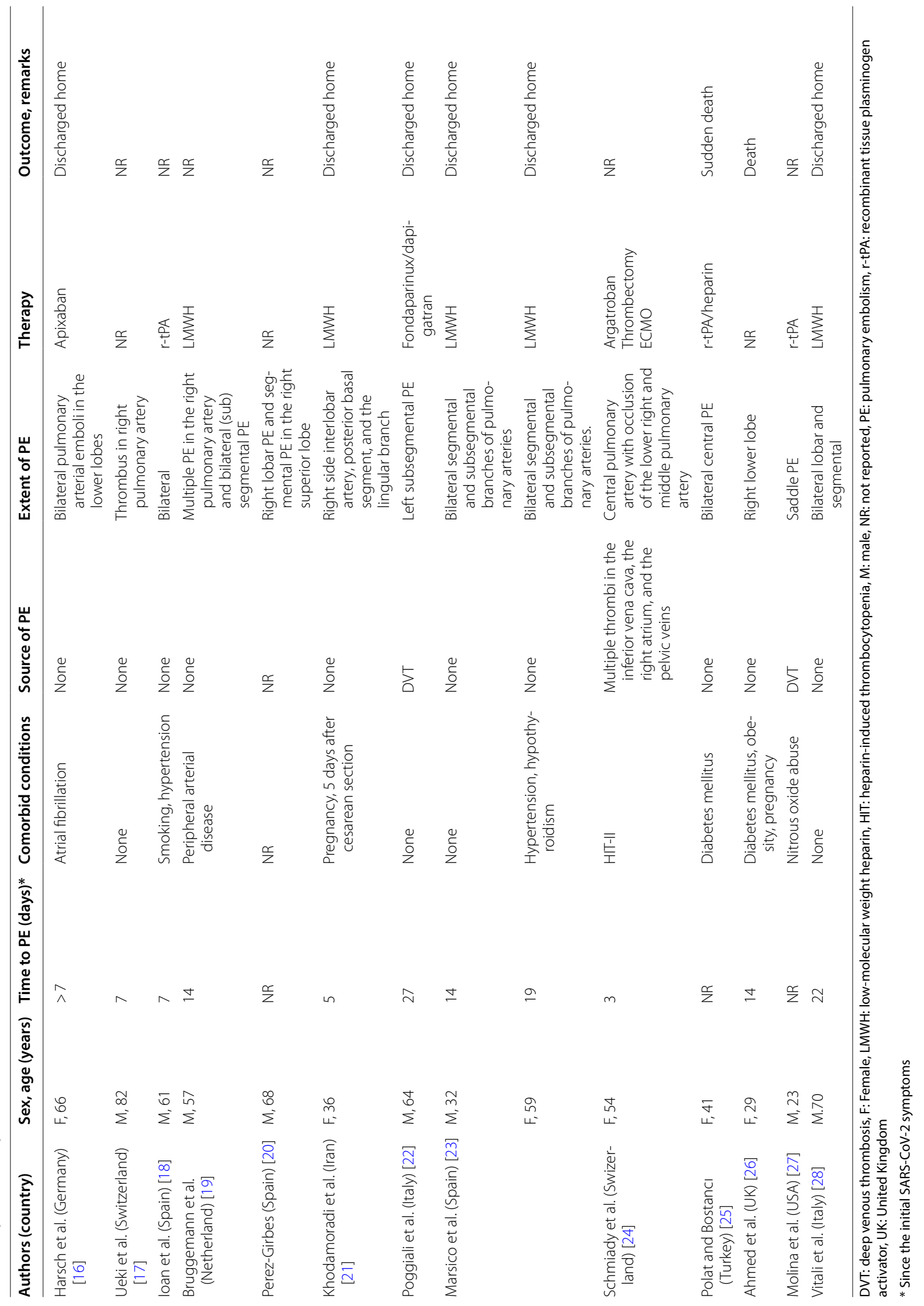




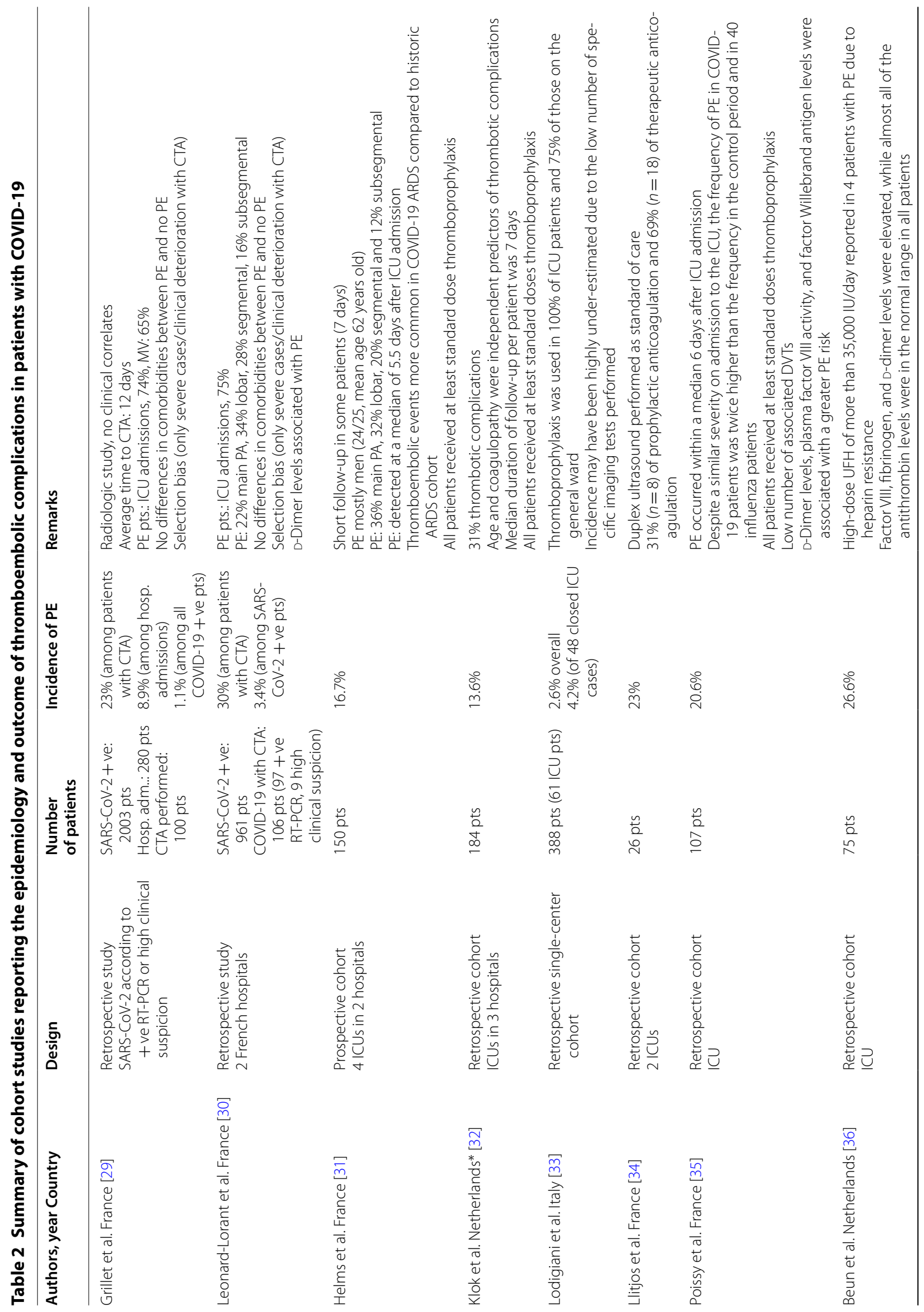




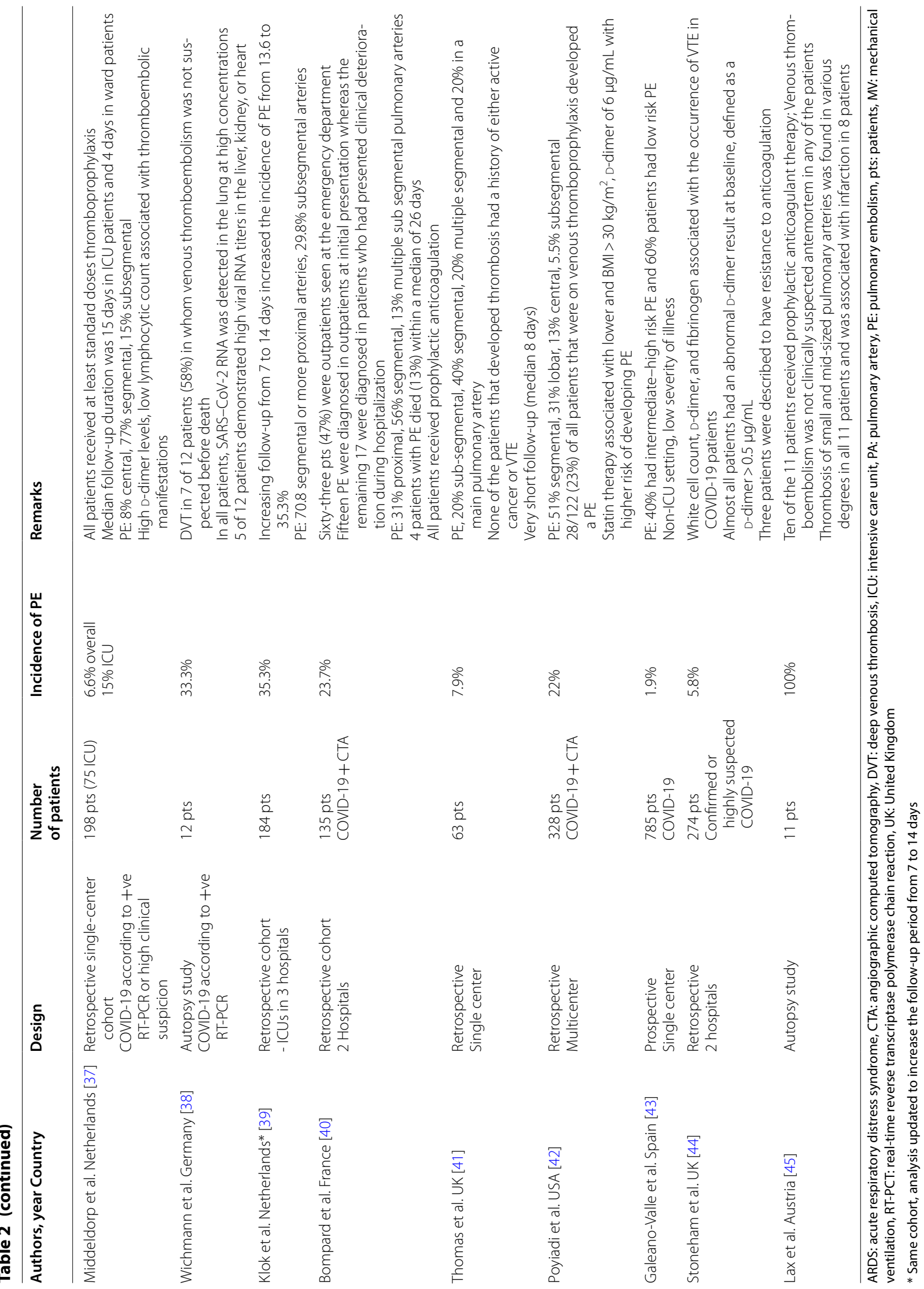


and symptoms of DVT, together with markedly elevated D-Dimer levels may be good candidates for diagnostic ultrasound assessment.

\section{Pathophysiology of PE in COVID-19 The hypercoagulable state in COVID-19}

The hypercoagulable state in COVID-19 was confirmed in a study by Han et al., in which higher levels of D-dimer, fibrinogen, and fibrinogen degradation products [46], prolonged prothrombin time (PT), international normalized ratio (INR), and thrombin time (TT) were also noted in patients with COVID-19 [47]; these abnormalities have been associated with poor prognosis in patients infected with SARS-CoV-2 [48]. Oudkerk et al. suggest that the very high D-dimer levels observed in COVID-19 patients are not only secondary to systemic inflammation, but also reflect true thrombotic disease, possibly induced by cellular activation that is triggered by the virus [50]. Furthermore, Cui et al. demonstrated that a cut-off value of $3.0 \mu \mathrm{g} / \mathrm{mL}$ for D-dimer had sensitivity, specificity and negative predictive values of $76.9 \%, 94.9 \%$ and $92.5 \%$ to predict VTE, respectively [51]. After receiving anticoagulant therapy, the level of D-dimer decreased gradually, showing that $\mathrm{D}$-dimer levels may not only predict thrombosis but also monitor the effectiveness of anticoagulant therapy. Nonetheless, D-dimer levels may not be a reliable predictor of VTE but rather a marker of poor overall outcome [4, 9] [52]. Indeed, Lionard-Lorant et al. showed that D-dimer greater than $2660 \mu \mathrm{g} / \mathrm{L}$ is highly sensitive $(100 \%, 95 \%$ CI $88-100)$ but not specific $(67 \%$, 95\% CI 52-79) to detect PE in COVID-19 patients [30]. Therefore, routine screening for VTE based on elevated D-dimer levels was not recommended in the most recent guidelines of the ISTH [49].

Viral infections may predispose to VTE [51], activating systemic inflammatory response that in turn causes an imbalance between procoagulant and anticoagulant effects [52]. Coagulation pathways and immune system are strictly linked. Clot formation should limit the loss of blood and immune components [53]. Meanwhile, a blood clot can slow down microorganism invasion of the circulation [53]. Indeed, immunocompromised individuals have been suggested to have had less pulmonary complications when infected with COVID-19 [53]. Thrombin and platelets play a key role in the relationship between immune system and coagulation. On the one hand, thrombin directly links the clotting pathways to the innate immune response [54]. On the other hand, various granular constituents of the platelets show antimicrobial and chemotactic properties [55]. The interaction between coagulation and inflammatory pathways in the bronchoalveolar compartment, also known as the "bronchoalveolar hemostasis" [56] could partially explain thrombotic complications in COVID-19 patients.

\section{Phenotypes and possible pathophysiologic mechanisms} At least two main phenotypes of COVID-19 patients with thrombotic lung injury can be identified: patients affected by "ordinary" VTE and patients showing pulmonary microthrombosis (PMT). Since DVT or other sources of VTE were not consistently found in COVID19 patients with PE, PMT could be the result of local hypercoagulability rather than secondary to embolization from the lower limbs [53]. Formation of thrombi in the microvasculature may be a part of the physiological effort to limit the viral load. Indeed, viral invasion induces an intense inflammation of the lungs which in turn triggers a local activation of hemostasis driven by the interaction between platelets and endothelium [53]. It has been speculated that a possible cornerstone of microthrombi generation during COVID-19 is related to endothelial cells' dysfunction $[57,58]$.

Interestingly, the coagulation activation pattern in COVID-19 ARDS patients in the ICU was not the same as in non-COVID-19 ARDS patients [31]. Whereas D-dimers levels were less elevated, PT, activated partial thromboplastin time (aPTT), and AT were within normal ranges, and fibrinogen was higher. This pattern differs also from that observed in patients with septic shock, who frequently develop disseminated intravascular coagulation (DIC) [59], Helms et al. reported that no COVID19 patient was diagnosed with DIC using ISTH "overt" score [31]. The underlying mechanisms of COVID-19-induced coagulopathy may be, therefore, different from that reported in other patients with sepsis. This may also explain the different phenotypes observed in COVID-19 patients, with predominant thromboembolic manifestations rather than bleeding tendency.

Several mechanisms may contribute to a hypercoagulable state [60] and PMT during COVID-19 [46] (Fig. 1). First, the direct and indirect pathologic consequences of COVID-19, such as severe hypoxia, preexisting comorbidities, and associated organ dysfunction can predispose to hemostatic abnormalities, including DIC [47]. Hypoxia can predispose to thrombosis by increasing blood viscosity and via a hypoxia-inducible transcription factor-dependent signaling pathway [61]. The risk of VTE is also associated with individual patient-related risk factors, such as age, immobilization, obesity, past history of personal or familial VTE, cancer, sepsis, respiratory or heart failure, pregnancy, stroke, trauma, or recent surgery. ICU-specific risk factors may also contribute to this risk, including but not limited to sedation, immobilization, vasopressor administration, and use of central venous catheters [60]. Second, endothelial dysfunction, 


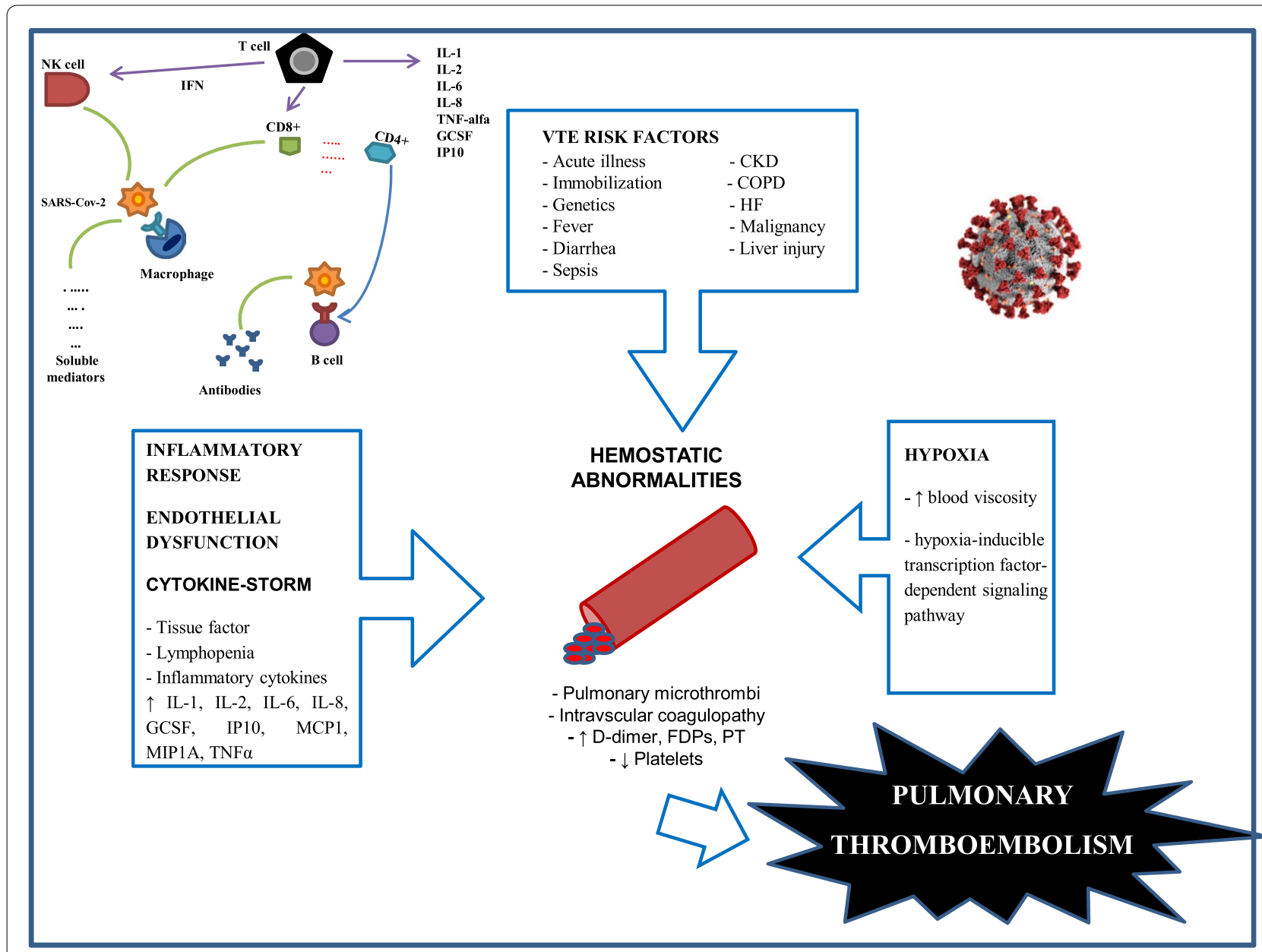

Fig. 1 Schematic representation of the possible pathophysiologic mechanisms underlying pulmonary embolism (PE) in patients with coronavirus disease-2019 (COVID-19). CD: CD receptor, CKD: chronic renal failure, COPD: chronic obstructive pulmonary disease, FDP: fibrin degradation products, GCSF: granulocyte-colony stimulating factor, HF: heart failure IFN: interferon, IL: interleukin, IP: interferon-gamma induced protein, MCP: monocyte chemotactic protein, MIP: macrophage inflammatory protein, NK: natural killer cells, PT: prothrombin time, SARS CoV-2: acute respiratory syndrome coronavirus 2, TNF alpha: tumor necrosis factor alpha

von Willebrand factor (vWF) elevation, Toll-like receptor activation, and tissue-factor pathway activation [62] may induce proinflammatory and procoagulant effects through complement activation and cytokine release [50], resulting in a dysregulation of the coagulation cascade with the subsequent formation of intra-alveolar or systemic fibrin clots. This may be explained, at least in part, by the increased plasminogen activator inhibitor 1 (PAI-1) levels with subsequent decrease of the fibrinolytic activity in these patients [63]. Helms et al. analyzed the occurrence of thromboembolic events in all patients admitted to four French ICUs for COVID-19-associated ARDS [31]. They noted that vWF activity and vWF antigen (vWF:Ag) were considerably increased, as was factor VIII. Furthermore, 50 of the 57 patients tested (87.7\%) had positive lupus circulating anticoagulants during their
ICU stay. Third, the release of high plasma levels of proinflammatory cytokines (IL-2, IL-6, IL-7, IL-8, granulocyte colony-stimulating factor, interferon gamma-induced protein 10 (IP10), monocyte chemotactic protein-1 (MCP1), macrophage inflammatory protein 1A (MIP1A) and tumor necrosis factor (TNF- $\alpha)$-the so-called "cytokine storm", which is a common feature of sepsiscause secondary development of hemophagocytic lymphohistiocytosis with activation of blood coagulation, increased risk of intravascular microthrombosis and secondary local consumption coagulopathy [50], promoting the occurrence of VTE. Finally, the interactions between different types of blood cell (macrophages, monocytes, endothelial cells, platelets and lymphocytes) could play a critical role in the procoagulant effect of viral infections. For example, platelet activation upon antigen recognition 
may facilitate the pathogen's clearance by white blood cell activation and clot formation [62]. This may be modulated by the neutrophil extracellular traps (NETs), which are induced by platelets and play an important role in sepsis-associated hypercoagulability [64]. In agreement with this assumption, Middeldorp et al. found that white blood cell count, higher neutrophil-to-lymphocyte ratio and a higher D-dimer level are independent risk factors associated with VTE [37].

\section{The role of endothelial injury}

Endothelial cells represent almost a third of the cells in the broncho-alveolar units [65]. Endothelial dysfunction refers to a systemic condition in which the endothelium loses some its physiological properties such as promoting vasodilation, fibrinolysis, and anti-aggregation [65]. This condition could be induced in COVID-19 patients through general and virus-related factors. Comorbid conditions, such as hypertension, diabetes and acute kidney injury are usually linked to endothelial damage and may, therefore, promote COVID-19-related complications [65]. Virus-related factors may also induce endothelial damage through direct viral penetration in endothelial cells, the effects of cytokines on the endothelium, and the release of von Willebrand factor by endothelial cells. Endothelial cells possess the key receptors for the SARS$\mathrm{CoV}-2$ (i.e., the angiotensin-converting enzyme-2 receptors), that facilitate viral penetration [66]. They also express other receptors shared with SARS-CoV-2, such as serine protease 2 and sialic acid receptors [58]. Accordingly, endothelial cell infection results in some cytopathic modifications following viral penetration. In particular, vascular obliteration and thrombosis of small and middle size vessels are common findings in PMT secondary to COVID-19. Furthermore, the proinflammatory cytokines released in patients with COVID-19 promote vascular endothelial cell apoptosis, PMT, vascular leakage, alveolar edema, and ultimately hypoxia [66]. Proinflammatory cytokines can also increase the expression of adhesion molecules that in turn results in endothelial activation, procoagulant effects and pro-adhesive changes [67]. All these molecular changes can impaire microvascular flow and, consequently, alter ventilation/perfusion ratio. It has been also postulated that endothelial damage and PMT could be induced by an imbalance between insufficient ADAMTS-13 (a disintegrin and metalloproteinase with a thrombospondin type 1 motif, member 13) and excessive exocytosis of ultra large von Willebrand factor multimers (ULVWF) from Weibel-Palade bodies present in endothelial cells [57]. ULVWF are anchored to the endothelial surface and can recruit platelets inducing microthrombogenesis [57]. Subsequently, platelets are rapidly activated causing platelet aggregation and leukocytes recruitment in a P-selectin-dependent manner [57]. These aggregates continue to grow until they become sufficiently large to induce extended PMT.

\section{Therapeutic implications}

The accumulating evidence suggests that PE is a significant complication in patients with COVID-19, so that indications and modalities for prophylactic and therapeutic use of antithrombotic agents should be revisited. Preliminary data from 449 consecutive patients with severe COVID-19 demonstrated that prophylactic doses of heparin were associated with improved survival in a subgroup of patients meeting criteria for sepsis-induced coagulopathy or with markedly elevated D-dimer levels [68]. The ISTH and the American Society of Hematology (ASH) $[47,49,60,69]$ have recently recommended that a prophylactic dose of LMWH (40 mg qd) [70] or subcutaneous unfractionated heparin (5000 IU tid) - should be started in all suspected or confirmed COVID-19 patients admitted to the hospital. In patients with known heparininduced thrombocytopenia, fondaparinux [70,71], which was found to be effective in reducing sepsis-derived coagulopathy in an animal model [72], should be used. If pharmacological prophylaxis is contraindicated, mechanical VTE prophylaxis (e.g., intermittent pneumatic compression) should be considered in immobilized patients [47]; combined pharmacologic and mechanical prophylaxis is not generally recommended [71]. Although limited data are available, it is reasonable to consider pharmacological thromboprophylaxis in patients admitted to hospital with COVID-19 infection, even in pregnant women, since they are likely to be at an increased risk of VTE [47]. The use of and intermediate dose of LMWH (e.g., enoxaparin 4000 IU subcutaneously every $12 \mathrm{~h}$ ) can be considered on an individual basis in patients with multiple risk factors for VTE [73] and in critically ill patients due to the higher incidence of $\mathrm{PE}$ in this population [29-41]. In obese patients, higher weight-based doses may be needed, with doses of 7500 IU UFH three times daily or enoxaparin $40 \mathrm{mg}$ twice daily $[74,75]$. Figure 2 represents a flow diagram of the recommended procedure for initiating thromboprophylaxis in patients with coronavirus disease-2019.

Therapeutic anticoagulation is the cornerstone in the management of patients with PE. Selection of an appropriate agent and correct dosage requires consideration of the underlying comorbidities, such as renal or hepatic dysfunction, thrombocytopenia, and gastrointestinal tract function [47]. Zhai et al. recommend LMWH (e.g., subcutaneous enoxaparin $100 \mathrm{IU} / \mathrm{kg}$, twice daily or $150 \mathrm{IU} / \mathrm{kg}$ once daily, or nadroparin $86 \mathrm{IU} / \mathrm{kg}$ twice daily) as a first-line treatment [76]. In severe renal impairment, or if it is expected that invasive procedures will be 


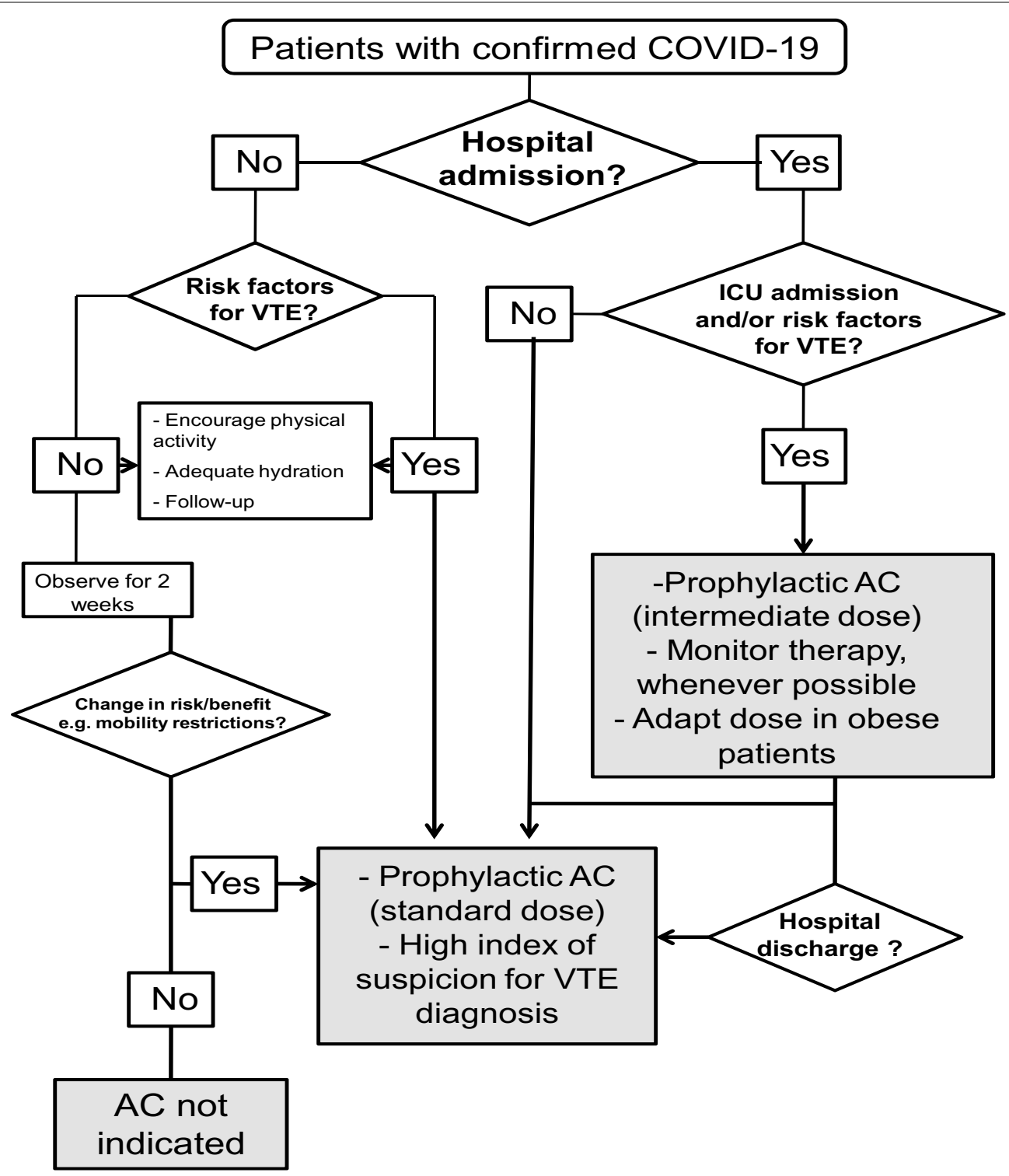

Fig. 2 Flow diagram of the recommended procedure for initiating thromboprophylaxis in patients with coronavirus disease-2019 (COVID-19). The choice of the appropriate method for anticoagulation (AC) should be based on individual risk/benefit assessment (see text for details). COVID-10: coronavirus disease-2019, VTE: venous thromboembolism

required, intravenous UFH followed by the subcutaneous route is more appropriate, with regular monitoring for anticoagulation dose adjustment. Direct oral anticoagulants (DOACs) are an option only after the acute phase in stable patients, with the well-known benefits of lack of need for monitoring, which facilitates timely discharge from the hospital and outpatient management. However, a potential risk of DOACs, especially in the setting of organ dysfunction, may include clinical deterioration and lack of effective reversal agents at some centers [47]. Geert-Jan Geersing et al. provided a guidance document for switching from vitamin $\mathrm{K}$ antagonists (VKAs) to a DOAC in current emergency settings [77]. They underscore the need to switch with care and caution, and the importance of not making this choice just for simplicity, because it may contribute to errors like overlapping periods of anticoagulation, terminating VKA without correctly starting DOACs, and lack of explanation to the patient for the reasons for such drug changes, thus create a potential risk for thromboembolism or bleeding [78]. The use of catheter-directed therapies during the current outbreak should be limited to the most critical situations 
[47]. Recurrent PE despite optimal anticoagulation and clinically significant VTE in the setting of absolute contraindications to anticoagulation would be among the few scenarios in which placement of an inferior vena cava filter may be considered $[47,79]$, and even in these cases, anticoagulation should be resumed as soon as feasible. In patients requiring therapeutic doses of LMWH or receiving a DOAC, renal function should be monitored and anti-factor Xa or plasma DOAC levels should be monitored.

Intermediate-risk hemodynamically stable patients (intermediate-low risk or intermediate-high risk PE according to the European Society of Cardiology (ESC) classification; sub-massive PE according to prior classifications) should be managed initially with anticoagulation and close monitoring. If the condition suddenly worsens and there are signs of overt hemodynamic instability (massive or high-risk PE with hypotension or sudden cardiac arrest) and evidence on bedside echocardiography of new onset increased right-ventricular load or pulmonary arterial hypertension, thrombolytic therapy should be initiated urgently $[47,76]$. In case of refractory shock or cardiac arrest, extra corporeal membrane oxygenator (ECMO) could be an option, in combination with surgical embolectomy or catheter-directed treatment, as rescue initiatives [76].

Since the procoagulant effect of COVID-19 may extend some weeks after hospital discharge of apparently stable, asymptomatic patients. It would be prudent, therefore, to have a high degree of clinical suspicion of PE in COVID19 patients readmitted to the hospital after surviving an initial hospitalization. Decisions about extending prophylaxis with LMWH after hospital discharge from acute medical illness should be made by balancing the reduced risk of VTE with the risk of increased bleeding events, including major bleeding. In the absence of high-quality data, pharmacological prophylaxis in this context should be reserved for patients at highest risk, including those with limited mobility and history of prior VTE or active malignancy [47]. As recommended by the Italian Society on Thrombosis and Haemostasis (SISET), prophylactic anticoagulation should be maintained at home for 7-14 days after hospital discharge or in the pre-hospital phase during home self isolation, in case of pre-existing or persisting VTE risk factors (i.e., reduced mobility, body mass index $(\mathrm{BMI})>30$, previous VTE, active cancer, etc.) [73].

\section{Summary and conclusions}

Patients with COVID-19 are at increased risk of developing PE which may occur in up to one-third of critically ill COVID-19 patients requiring ICU admission. Thromboprophylaxis should therefore be started in COVID-19 patients admitted to the hospital and intermediate therapeutic doses of anticoagulants can be considered in patients requiring ICU admission or those with multiple risk factors for VTE. Extending thromboprophylaxis after hospital discharge or in the prehospital phase during home self isolation should be done according to a meticulous risk/benefit assessment, balancing the reduced risk of VTE with the risk of increased bleeding events. Therapeutic anticoagulation is the cornerstone in the management of patients with PE. Selection of an appropriate agent and correct dosage requires consideration of underlying comorbidities and organ dysfunction.

\begin{abstract}
Abbreviations
ADAMTS-13: A disintegrin and metalloproteinase with a thrombospondin type 1 motif, member 13; aPTT: Activated partial thromboplastin time; ARDS: Acute respiratory distress syndrome; ASH: American Society of Hematology; BMI: Body mass index; ECMO: Extra corporeal membrane oxygenator; CTA : Computer tomographic angiography; COVID-19: Corona virus disease-2019; DIC: Disseminating intravascular coagulation; DOAC: Direct oral anticoagulants; DVT: Deep vein thrombosis; ESC: European Society of Cardiology; ICU: Intensive care unit; LL: Interleukin; INR: International normalized ratio; IP: Interferon-gamma induced protein; ISTH: International Society of Thrombosis and Haemostasis; I.U.: International unit; IQ: interquartile range; LMWH: Low molecular weight heparin; MCP: Monocyte chemotactic protein; MIP: Macrophage inflammatory protein; NETs: Neutrophil extracellular traps; PMT: Pulmonary microthrombosis; PT: Prothrombin time; PAl-1: Plasminogen activator inhibitor 1; PE: Pulmonary embolism; RT-PCR: Real-time reverse transcription polymerase chain reaction; r-tPA: Recombinant tissue-type plasminogen activator; SARS-CoV-2: Severe Acute Respiratory Syndrome Coronavirus 2; SISET: Italian Society on Thrombosis and Haemostasis; TT: Thrombin time; ULVWF: von Willebrand factor multimers; VTE: Venous thromboembolism; VKA: Vitamin K antagonist; VWF: Von Willebrand factor; VWF:Ag: vWF antigen.
\end{abstract}

\section{Acknowledgements}

None.

\section{Authors' contributions}

$Y S, I A, V M R, A K, M B$, and $M L$, designed the scientific work. YS, SB, EA, and MG reviewed the literature. $Y S, E A, M G, M L, G P, T T, G D$, and $L Z$ wrote the first draft of the manuscript. All the authors reviewed and revised, the submitted manuscript. All authors read and approved the final manuscript.

Funding

Open Access funding enabled and organized by Projekt DEAL.

Availability of data and materials

Not applicable.

Ethics approval and consent to participate

Not applicable.

Consent for publication

Not applicable.

\section{Competing interests}

The authors declare that they do not have conflict of interests in relation to this manuscript.

\section{Author details}

${ }^{1}$ Dept. of Anesthesiology and Intensive Care Medicine, Jena University Hospital, Am Klinikum 1, 07743 Jena, Germany. ${ }^{2}$ Intermediate Care Unit, Emergency Department, Ospedale Guglielmo da Saliceto, Piacenza, Italy.

${ }^{3}$ Service d'Anesthésie et de Réanimation, Aix Marseille Université, Assistance Publique Hôpitaux Universitaires de Marseille, Hôpital Nord, Marseille, France. 
${ }^{4}$ Dipartimento di Scienze Mediche e Chirurgiche, Anesthesia and Intensive Care Medicine, Alma Mater Studiorum, Università di Bologna, Policlinico di Sant'Orsola, Bologna, Italy.

Received: 25 May 2020 Accepted: 6 September 2020 Published online: 16 September 2020

\section{References}

1. Zhu N, Zhang D, Wang W, Li X, Yang B, Song J, et al. A novel coronavirus from patients with pneumonia in China, 2019. N Engl J Med. 2020;382(8):727-33.

2. Danzi GB, Loffi M, Galeazzi G, Gherbesi E. Acute pulmonary embolism and COVID-19 pneumonia: a random association? Eur Heart J. 2020;41:1858.

3. Cellina M, Oliva G. Acute pulmonary embolism in a patient with COVID19 pneumonia. Diagn Interv Imaging. 2020;101:325-6.

4. Ullah W, Saeed R, Sarwar U, Patel R, Fischman DL. COVID-19 complicated by acute pulmonary embolism and right-sided heart failure. JACC Case Rep. 2020;2:1379-82.

5. Casey K, Iteen A, Nicolini R, Auten J. COVID-19 pneumonia with hemoptysis: acute segmental pulmonary emboli associated with novel coronavirus infection. Am J Emerg Med. 2020;38:1544.e1-3.

6. Foch E, Allou N, Vitry T, Masse L, Allyn J, Andre M, et al. Pulmonary embolism in returning traveler with COVID-19 pneumonia. J Travel Med. 2020;27:taaa63.

7. Rotzinger DC, Beigelman-Aubry C, von Garnier C, Qanadli SD. Pulmonary embolism in patients with COVID-19: time to change the paradigm of computed tomography. Thromb Res. 2020;190:58-9.

8. Fabre O, Rebet O, Carjaliu I, Radutoiu M, Gautier L, Hysi I. Severe acute proximal pulmonary embolism and COVID-19: a word of caution. Ann Thorac Surg. 2020. https://doi.org/10.1016/j.athoracsur.2020.04.005.

9. Sulemane S, Baltabaeva A, Barron AJ, Chester R, Rahman-Haley S. Acute pulmonary embolism in conjunction with intramural right ventricular thrombus in a SARS-CoV-2-positive patient. Eur Heart J Cardiovasc Imaging. 2020;21:1054

10. Audo A, Bonato V, Cavozza C, Maj G, Pistis G, Secco GG. Acute pulmonary embolism in SARS-CoV-2 infection treated with surgical embolectomy. Ann Thorac Surg. 2020. https://doi.org/10.1016/j.athoracsur.2020.04.013.

11. Le Berre A, Marteau V, Emmerich J, Zins M. Concomitant acute aortic thrombosis and pulmonary embolism complicating COVID-19 pneumonia. Diagn Interv Imaging. 2020;101:321-2.

12. Jafari R, Cegolon L, Jafari A, Kashaki M, Otoukesh B, Ghahderijani BH, et al. Large saddle pulmonary embolism in a woman infected by COVID-19 pneumonia. Eur Heart J. 2020;41:2133.

13. Griffin DO, Jensen A, Khan M, Chin J, Chin K, Saad J, et al. Pulmonary embolism and increased levels of D-dimer in patients with coronavirus disease. Emerg Infect Dis. 2020;26(8):1941.

14. Martinelli I, Ferrazzi E, Ciavarella A, Erra R, Iurlaro E, Ossola M, et al. Pulmonary embolism in a young pregnant woman with COVID-19. Thromb Res. 2020;191:36-7.

15. Lushina N, Kuo JS, Shaikh HA. Pulmonary, cerebral, and renal thromboembolic disease associated with COVID-19 infection. Radiology. 2020;289:E181-3.

16. Harsch IA, Skiba M, Konturek PC. SARS-CoV-2 pneumonia and pulmonary embolism in a 66-year-old female. Pol Arch Intern Med. 2020;130:438-9.

17. Ueki Y, Otsuka T, Windecker S, Raber L. ST-elevation myocardial infarction and pulmonary embolism in a patient with COVID-19 acute respiratory distress syndrome. Eur Heart J. 2020:41:2134.

18. Ioan AM, Durante-Lopez A, Martinez-Milla J, Perez-Calvo C, Santos A Pulmonary embolism in COVID-19. When nothing is what it seems. Rev Esp Cardiol. 2020;73:665-7.

19. Bruggemann $R$, Gietema $H$, Jallah B, Ten Cate $H$, Stehouwer $C$, Spaetgens B. Arterial and venous thromboembolic disease in a patient with COVID19: a case report. Thromb Res. 2020;191:153-5.

20. Perez-Girbes A. Acute pulmonary embolism and Covid-19: a common association in seriously ill patients? Arch Bronconeumol. 2020;56:34

21. Khodamoradi Z, Boogar SS, Shirazi FKH, Kouhi P. COVID-19 and Acute pulmonary embolism in postpartum patient. Emerg Infect Dis. 2020:26(8):1937-9.
22. Poggiali E, Bastoni D, loannilli E, Vercelli A, Magnacavallo A. Deep vein thrombosis and pulmonary embolism: two complications of COVID-19 pneumonia? Eur J Case Rep Intern Med. 2020;7(5):001646.

23. Marsico S, Espallargas Gimenez I, Carbullanca Toledo SJ, Del Carpio Bellido LA, Maiques Llacer JM, Zuccarino F. Pulmonary infarction secondary to pulmonary thromboembolism in COVID-19 diagnosed with dualenergy CT pulmonary angiography. Rev Esp Cardiol. 2020;73:672-4.

24. Schmiady MO, Sromicki J, Kucher N, Ouda A. Successful percutaneous thrombectomy in a patient with COVID-19 pneumonia and acute pulmonary embolism supported by extracorporeal membrane oxygenation. Eur Heart J. 2020;41:3107.

25. Polat V, Bostanci Gl. Sudden death due to acute pulmonary embolism in a young woman with COVID-19. J Thromb Thrombolysis. 2020. https:// doi.org/10.1007/s11239-020-02132-5.

26. Ahmed I, Azhar A, Eltaweel N, Tan BK. First Covid-19 maternal mortality in the UK associated with thrombotic complications. Br J Haematol. 2020;190:e37-8.

27. Molina MF, AI Saud AA, Al Mulhim AA, Liteplo AS, Shokoohi H. Nitrous oxide inhalant abuse and massive pulmonary embolism in COVID-19. Am J Emerg Med. 2020:38:1549.e1-2.

28. Vitali C, Minniti A, Caporali R, Del Papa N. Occurrence of pulmonary embolism in a patient with mild clinical expression of COVID-19. Thromb Res. 2020;192:21-2.

29. Grillet F, Behr J, Calame P, Aubry S, Delabrousse E. Acute pulmonary embolism associated with COVID-19 pneumonia detected by pulmonary CT angiography. Radiology. 2020;296:E186-8.

30. Leonard-Lorant I, Delabranche X, Severac F, Helms J, Pauzet C, Collange O, et al. Acute pulmonary embolism in COVID-19 patients on CT angiography and relationship to D-dimer levels. Radiology. 2020;296:E189-91.

31. Helms J, Tacquard C, Severac F, Leonard-Lorant I, Ohana M, Delabranche $X$, et al. High risk of thrombosis in patients with severe SARS-CoV-2 infection: a multicenter prospective cohort study. Intensive Care Med. 2020. https://doi.org/10.1007/s00134-020-06062-x.

32. Klok FA, Kruip M, van der Meer NJM, Arbous MS, Gommers D, Kant KM, et al. Incidence of thrombotic complications in critically ill ICU patients with COVID-19. Thromb Res. 2020;191:145-7.

33. Lodigiani C, lapichino G, Carenzo L, Cecconi M, Ferrazzi P, Sebastian T, et al. Venous and arterial thromboembolic complications in COVID-19 patients admitted to an academic hospital in Milan. Italy. Thromb Res. 2020:191:9-14.

34. Llitjos JF, Leclerc M, Chochois C, Monsallier JM, Ramakers M, Auvray M, et al. High incidence of venous thromboembolic events in anticoagulated severe COVID-19 patients. J Thromb Haemost. 2020;18:1743-6.

35. Poissy J, Goutay J, Caplan M, Parmentier E, Duburcq T, Lassalle F, et al. Pulmonary embolism in COVID-19 patients: awareness of an increased prevalence. Circulation. 2020;14:184-6.

36. Beun R, Kusadasi N, Sikma M, Westerink J, Huisman A. Thromboembolic events and apparent heparin resistance in patients infected with SARSCoV-2. Int J Lab Hematol. 2020:42:19-20.

37. Middeldorp S, Coppens M, van Haaps TF, Foppen M, Vlaar AP, Muller MCA et al. Incidence of venous thromboembolism in hospitalized patients with COVID-19. J Thromb Haemost. 2020;18:1995-2002.

38. Wichmann D, Sperhake JP, Lutgehetmann M, Steurer S, Edler C, Heinemann A, et al. Autopsy findings and venous thromboembolism in patients with COVID-19: a prospective cohort study. Ann Intern Med. 2020. https://doi.org/10.7326/M20-2003.

39. Klok FA, Kruip M, van der Meer NJM, Arbous MS, Gommers D, Kant KM, et al. Confirmation of the high cumulative incidence of thrombotic complications in critically ill ICU patients with COVID-19: an updated analysis. Thromb Res. 2020;191:148-50.

40. Bompard F, Monnier H, Saab I, Tordjman M, Abdoul H, Fournier L, et al. Pulmonary embolism in patients with Covid-19 pneumonia. Eur Respir J. 2020;56:2001365

41. Thomas W, Varley J, Johnston A, Symington E, Robinson M, Sheares K, et al. Thrombotic complications of patients admitted to intensive care with COVID-19 at a teaching hospital in the United Kingdom. Thromb Res. 2020;191:76-7.

42. Poyiadi N, Cormier P, Patel PY, Hadied MO, Bhargava P, Khanna K, et al. Acute pulmonary embolism and COVID-19. Radiology. 2020. https://doi org/10.1148/radiol.2020201955. 
43. Galeano-Valle F, Oblitas CM, Ferreiro-Mazon MM, Alonso-Munoz J, Del Toro-Cervera J, Demelo-Rodriguez P. Antiphospholipid antibodies are not elevated in patients with severe COVID-19 pneumonia and venous thromboembolism. Thromb Res. 2020;192:113-5.

44. Stoneham SM, Milne KM, Nuttal E, Frew GH, Sturrock BR, Sivaloganathan $\mathrm{H}$, et al. Thrombotic risk in COVID-19: a case series and case-control study. Clin Med. 2020;20:e76-81.

45. Lax SF, Skok K, Zechner P, Kessler HH, Kaufmann N, Koelblinger C, et al. Pulmonary arterial thrombosis in COVID-19 with fatal outcome: results from a prospective, single-center, clinicopathologic case series. Ann Intern Med. 2020. https://doi.org/10.7326/M20-2566.

46. Rouhezamin MR, Haseli S. Diagnosing pulmonary thromboembolism in COVID-19: a stepwise clinical and imaging approach. Acad Radiol. 2020:27:896-7.

47. Bikdeli B, Madhavan MV, Jimenez D, Chuich T, Dreyfus I, Driggin E, et al. COVID-19 and thrombotic or thromboembolic disease: implications for prevention, antithrombotic therapy, and follow-up. J Am Coll Cardiol. 2020;75(2950):2973

48. Tang N, Li D, Wang X, Sun Z. Abnormal coagulation parameters are associated with poor prognosis in patients with novel coronavirus pneumonia. J Thromb Haemost. 2020;18:844-7.

49. Thachil J, Tang N, Gando S, Falanga A, Cattaneo M, Levi M, et al. ISTH interim guidance on recognition and management of coagulopathy in COVID-19. J Thromb Haemost. 2020;18:1023-6.

50. Oudkerk M, Buller HR, Kuijpers D, van Es N, Oudkerk SF, McLoud TC, et al. Diagnosis, prevention, and treatment of thromboembolic complications in COVID-19: report of the National Institute for Public Health of the Netherlands. Radiology. 2020. https://doi.org/10.1148/radiol.2020201629.

51. Cui S, Chen S, Li X, Liu S, Wang F. Prevalence of venous thromboembolism in patients with severe novel coronavirus pneumonia. J Thromb Haemost. 2020;18:1421-4

52. Lippi G, Favaloro EJ. D-Dimer is associated with severity of coronavirus disease 2019: a pooled analysis. Thromb Haemost. 2020;120(5):876-8.

53. Thachil J, Srivastava A. SARS-2 Coronavirus-associated hemostatic lung abnormality in COVID-19: is it pulmonary thrombosis or pulmonary embolism? Semin Thromb Hemost. 2020. https://doi. org/10.1055/s-0040-1712155.

54. Maas C, Renne T. Coagulation factor XII in thrombosis and inflammation. Blood. 2018;131(17):1903-9.

55. Morrell CN, Aggrey AA, Chapman LM, Modjeski KL. Emerging roles for platelets as immune and inflammatory cells. Blood. 2014;123(18):2759-67.

56. Glas GJ, Van Der Sluijs KF, Schultz MJ, Hofstra JJ, Van Der Poll T, Levi M. Bronchoalveolar hemostasis in lung injury and acute respiratory distress syndrome. J Thromb Haemost. 2013;11(1):17-25.

57. Varatharajah N, Rajah S. Microthrombotic complications of COVID-19 are likely due to embolism of circulating endothelial derived ultralarge von willebrand factor (eULVWF) decorated-platelet strings. Fed Pract. 2020;37(6):e1-2

58. Mosleh W, Chen K, Pfau SE, Vashist A. Endotheliitis and endothelial dysfunction in patients with COVID-19: its role in thrombosis and adverse outcomes. J Clin Med. 2020;9(6):1862.

59. Delabranche $X$, Quenot JP, Lavigne T, Mercier E, Francois B, Severac $F$, et al. Early detection of disseminated intravascular coagulation during septic shock: a multicenter prospective study. Crit Care Med. 2016;44(10):e930-9.

60. Kollias A, Kyriakoulis KG, Dimakakos E, Poulakou G, Stergiou GS, Syrigos K. Thromboembolic risk and anticoagulant therapy in COVID-19 patients: emerging evidence and call for action. Br J Haematol. 2020;189:846-7.

61. Gupta N, Wish JB. Hypoxia-Inducible Factor Prolyl Hydroxylase Inhibitors: a Potential New Treatment for Anemia in Patients With CKD. Am J Kidney Dis. 2017;69(6):815-26.

62. Giannis D, Ziogas IA, Gianni P. Coagulation disorders in coronavirus infected patients: COVID-19, SARS-CoV-1, MERS-CoV and lessons from the past. J Clin Virol. 2020;127:104362.
63. Wu YP, Wei R, Liu ZH, Chen B, Lisman T, Ren DL, et al. Analysis of thrombotic factors in severe acute respiratory syndrome (SARS) patients. Thromb Haemost. 2006;96(1):100-1.

64. Zucoloto AZ, Jenne CN. Platelet-neutrophil interplay: insights into neutrophil extracellular trap (NET)-driven coagulation in infection. Front Cardiovasc Med. 2019;6:85.

65. Sardu C, Gambardella J, Morelli MB, Wang X, Marfella R, Santulli G. Hypertension, thrombosis, kidney failure, and diabetes: is COVID-19 an endothelial disease? A comprehensive evaluation of clinical and basic evidence. J Clin Med. 2020;9(5):1417.

66. De Lorenzo A, Escobar S, Tibirica E. Systemic endothelial dysfunction: a common pathway for COVID-19, cardiovascular and metabolic diseases. Nutr Metab Cardiovasc Dis. 2020;30:1401-2.

67. Tong $M$, Jiang $Y$, Xia D, Xiong $Y$, Zheng $Q$, Chen F, et al. Elevated serum endothelial cell adhesion molecules expression in COVID-19 patients. J Infect Dis. 2020;222:894-8.

68. Tang N, Bai H, Chen X, Gong J, Li D, Sun Z. Anticoagulant treatment is associated with decreased mortality in severe coronavirus disease 2019 patients with coagulopathy. J Thromb Haemost. 2020;18:1094-9.

69. Spyropoulos AC, Levy JH, Ageno W, Connors JM, Hunt BJ, Iba T, et al. Scientific and standardization committee communication: clinical guidance on the diagnosis, prevention and treatment of venous thromboembolism in hospitalized patients with COVID-19. J Thromb Haemost. 2020;18:1859-65.

70. Obi AT, Barnes GD, Wakefield TW, Brown Rvt S, Eliason JL, Arndt E, et al. Practical diagnosis and treatment of suspected venous thromboembolism during COVID-19 pandemic. J Vasc Surg Venous Lymphat Disord. 2020;8:526-34.

71. Witt DM, Nieuwlaat R, Clark NP, Ansell J, Holbrook A, Skov J, et al. American Society of Hematology 2018 guidelines for management of venous thromboembolism: optimal management of anticoagulation therapy. Blood Adv. 2018;2(22):3257-91.

72. Keshari RS, Silasi R, Popescu NI, Georgescu C, Chaaban H, Lupu C, et al. Fondaparinux pentasaccharide reduces sepsis coagulopathy and promotes survival in the baboon model of Escherichia coli sepsis. J Thromb Haemost. 2020;18(1):180-90.

73. Marietta M, Ageno W, Artoni A, De Candia E, Gresele P, Marchetti M, et al. COVID-19 and haemostasis: a position paper from Italian Society on Thrombosis and Haemostasis (SISET). Blood Transfus. 2020;18:167-9.

74. Pannucci CJ, Fleming Kl, Holoyda K, Moulton L, Prazak AM, Varghese TK Jr. Enoxaparin $40 \mathrm{mg}$ per day is inadequate for venous thromboembolism prophylaxis after thoracic surgical procedure. Ann Thorac Surg. 2018;106(2):404-11.

75. Wang TF, Milligan PE, Wong CA, Deal EN, Thoelke MS, Gage BF. Efficacy and safety of high-dose thromboprophylaxis in morbidly obese inpatients. Thromb Haemost. 2014;111(1):88-93.

76. Zhai Z, Li C, Chen Y, Gerotziafas G, Zhang Z, Wan J, et al. Prevention and treatment of venous thromboembolism associated with coronavirus disease 2019 infection: a consensus statement before guidelines. Thromb Haemost. 2020;120:937-48.

77. GJ G, MV H, H TC, M K. Overzetten VKA naar DOAC tijdens corona epidemie.

78. Ten Cate H. Thrombosis management in times of COVID-19 epidemy; a Dutch perspective. Thromb J. 2020;18:7.

79. Kearon C, Akl EA, Ornelas J, Blaivas A, Jimenez D, Bounameaux H, et al. Antithrombotic therapy for VTE disease: CHEST guideline and expert panel report. Chest. 2016;149(2):315-52.

\section{Publisher's Note}

Springer Nature remains neutral with regard to jurisdictional claims in published maps and institutional affiliations. 